\title{
Eosinophilic esophagitis evoked by amino acid preparations in three brothers to a family with strong history of atopy
}

\author{
Asad Dajani ${ }^{1 *}$, Laura Kassym ${ }^{2}$ and Adnan Abu Hammour ${ }^{3}$ \\ ${ }^{1}$ Gastroenterology Division, Emirates Medical Association, Pan Arab Association of Gastroenterology, Sharjah, Dubai, UAE \\ ${ }^{2}$ Asad Dajani Specialized Clinic, Sharjah, UAE \\ ${ }^{3} \mathrm{Abu}$ Hammour Medical Center Dubai, UAE
}

\begin{abstract}
Eosinophilic esophagitis is increasingly recognized since it was described in 1978. It is an inflammatory disorder of the esophagus characterized by the accumulation of eosinophils in the epithelium leading to a range of symptoms that does not respond to PPIs. The mediated inflammatory response is similar to the milieu of bronchial asthma reaction however studies had documented food and aero-allergies in its causation with an evidence of disease remission in children fed on elemental diet. Seasonality and association with pollen count has also been demonstrated. We describe here, the case of three brothers from a family known to have atopic disorders who developed Eosinophilic Esophagitis at about the same time when they started using complex protein shakes and amino acid tablets meant for body building. Initially they did not respond to empiric PPIs but when diagnosed by endoscopy and histologic proof was documented they responded to topical steroids and a leukotriene analogue. Remission was maintained by eliminating the proteins and amino acids from their diet.
\end{abstract}

\section{Introduction}

Eosinophilic esophagitis (EoE) is a chronic, immune/antigen mediated disease, characterized clinically by dysphagia and histologically by eosinophil-predominant inflammation of the esophageal mucosa [1]. Epidemiologic data depends on medical awareness and the availability of endoscopy services. The incidence and prevalence has increased noticeably over the past years [2], In the general population the prevalence varies from 0.2 to $4 / 1000$ in the asymptomatic patients [3-5], but by endoscopy it is found in $5-16 \%$ in those who have relevant symptoms [6-8].

EoE is more common in males than females and can affect all races and ethnicities. Most of the patients are atopic with a familial association. There seems to be a stronger genetic component expression in EoE than other atopic diseases $[9,10]$. The risk recurrence ratio in the siblings for EoE is approximately 80 [11], compared with approximately 2 for asthma [12].

The disease is thought to be due to an allergic reaction to ingested food [13], the use of elemental diets with exclusion of certain amino acids had led to a significant clinical and histological improvement [14]. This was first concluded from the work of Kelly et al., who treated children with an elemental diet or amino acid-based formula [15]. Amino acid formulas are known now to be the most effective diet for EoE therapy, with a remarkable clinical and histological improvement rate over $96 \%$ of children [16-18]. The natural history of EoE is not well described yet; but previous studies [19-22] presume eventual progression of an untreated disease. Straumann et al. [23] prospectively studied 30 adults with EoE for a mean follow up 7.2 years (1.4-11.5) and found that dysphagia increased in $7 / 30$ (23.3\%), persisted in $11 / 30$ (36.7\%), improved in $11 / 30(36.7 \%)$ and only $1 / 30(3.4 \%)$ became asymptomatic.
Clinical features of EoE are variable in different age groups. Feeding intolerance, abdominal pain and vomiting are the most frequent symptoms among children. Adolescents and adults suffer from dysphagia and food bolus impaction. Laboratory parameters may show features of allergic disease like peripheral eosinophilia, a rise of total IgE, positive skin prick or allergen patch tests, or detection of $\operatorname{IgE}$ specific allergic antibodies. Endoscopy with biopsy of the esophageal mucosa showing extensive eosinophil infiltration is the indicative diagnosis [24].

The most typical endoscopic findings of EoE are, fixed or transient esophageal rings, linear furrows, white exudates, narrowing of the caliber of esophageal lumen [25]. For being defined histologically at least 15 eosinophils per high-power field should be found in esophageal mucosal biopsy from three different sites. EoE can be diagnosed if there are at least 15 eosinophils/hpf on esophageal biopsy performed after a high-dose 8-week PPI trial.

The treatment of EoE consists of an elimination diet and/or drug therapy. The amino-acid based formula is recognized to be the more successful in achieving clinical and histological remission than the targeted elimination diet and empiric elimination diet [26].

Topical corticosteroids as fluticasone, budesonide and ciclosonide are more preferable to avoid the side effects of systemic steroids. The

*Correspondence to: Asad Dajani, Gastroenterology Division, Emirates Medical Association, Pan Arab Association of Gastroenterology, Sharjah, Dubai, UAE, Tel: +971555727700; E-mail: aidajani@emirates.net.ae

Key words: endoscopy, leukotriene analogue, amino acid tablets

Received: June 05, 2018; Accepted: June 22, 2018; Published: June 26, 2018 
efficacy of other drug groups such as biologic agents, leukotriene antagonists, mast cell stabilizers and immune-modulators is still arguable and needs to be studied over the coming years [26].

\section{Case report}

FMA is a 24 years old Lebanese patient who presented with a two weeks history of progressive food impaction. Passage of solids and fluids would become difficult within minutes after ingesting them. The impaction resolves after 10-15 minutes. This was observed with most of the meals that he would take. History indicated that he had a sound healthy childhood and adolescence lest for atopic skin rash that used to appear from time to time. He is born to a first-degree relative marriage and his mother's side was known to have bronchial asthma, allergic rhinitis and atopic dermatitis amongst different siblings. Review of the other systems and clinical examination was unremarkable. Empiric high dose PPI given twice daily for 2 weeks did not help resolve the symptoms. Decision was to proceed with further investigation. Laboratory evaluation revealed an elevated CRP, peripheral eosinophilia (11.5\%) and a very high IgE (840 IU), all other lab parameters were normal. An upper GI endoscopy revealed classical features of Eosinophilic esophagitis (fixed circular contractions and diffuse oesophageal exudates). Biopsy from the upper, middle and lower oesophagus was conclusive of Eosinophilic esophagitis (Figures 1 and 2).

One week later his younger brother HMA, 19 years old, presented with a similar history of food impaction for an upper GI endoscopy, which had confirmed the same findings of Eosinophilic esophagitis. This brother had a history of bronchial asthma during childhood that resolved at the age of 14 .

At about the same time the elder brother AMA 26 years old developed a sudden severe bronchial asthma and was admitted to hospital with status asthmaticus. He also admitted to having the same complaint of food impaction. An EGD was done two weeks later which confirmed the diagnosis of EOE.
Relevant clinical features of the three brothers are summarized in table 1, figures 1 and 2, all other lab tests were non-indicative.

The family had moved recently to Dubai, where the three brothers joined a sports club for physical training. They were advised by their trainer to take protein body building supplements in the form of amino acid shake preparations together with branched chain amino acid tablets (combination of essential, conditionally essential and nonessential) amino acids. That was the only change in their life style.

\section{Discussion and conclusion}

This report presents three brothers belonging to a family with a strong history of atopy. They had several variable features during their childhood: atopic dermatitis (case 1), bronchial asthma (case 2) and urticaria with allergic rhinitis (case 3). Their younger sister has also same features of allergic dermatitis. They suddenly developed dysphagia with transient food impaction soon after they started taking concentrated protein shakes and amino acids as a nutritional supplement to achieve desired body building. The first case encountered was treated initially with a proton pump inhibitor on an empiric basis assuming that it was a case of dysphagia due to acid reflux. Having failed to respond to the treatment further evaluation was planned which proved that he was suffering from EoE. The diagnosis was easier in the second and third case due to similar background.

It is assumed that the protein concentrates which the three brothers were taking for the first time in their life had a possible contribution to the induction of the disease in a predisposed consanguineous family having a strong association with atopic diseases. The compounds they were using was so heterogeneous containing all types of amino acids, whey protein and flavours. It was the only change in their life style since they started this activity. The pathogenesis of EoE is still poorly understood. A possible association or overlap with a subset of patients having GERD may exist. Eosinophil derived inflammatory proteins (Il-6, PAF's, vasoactive peptides) induce LES relaxations and decrease esophageal contractions [27]. Acid/pepsin can damage tight junctions and lead to increased permeability with consequent antigen exposure

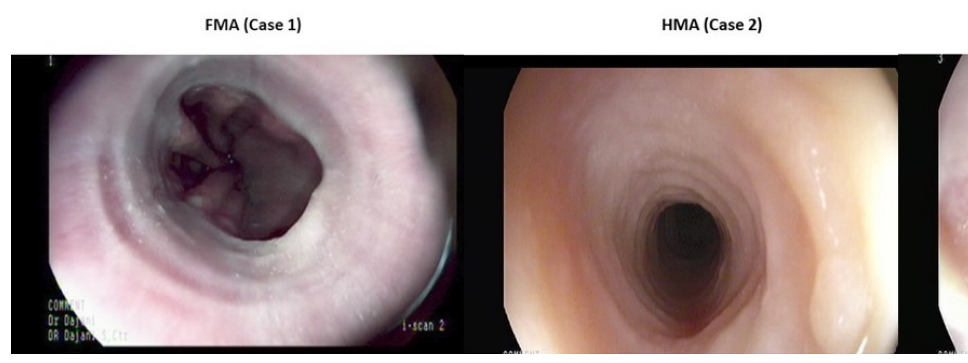

Figure 1. Endoscopic findings in the three cases

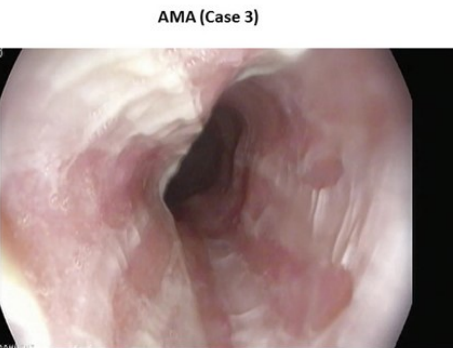

HMA AMA
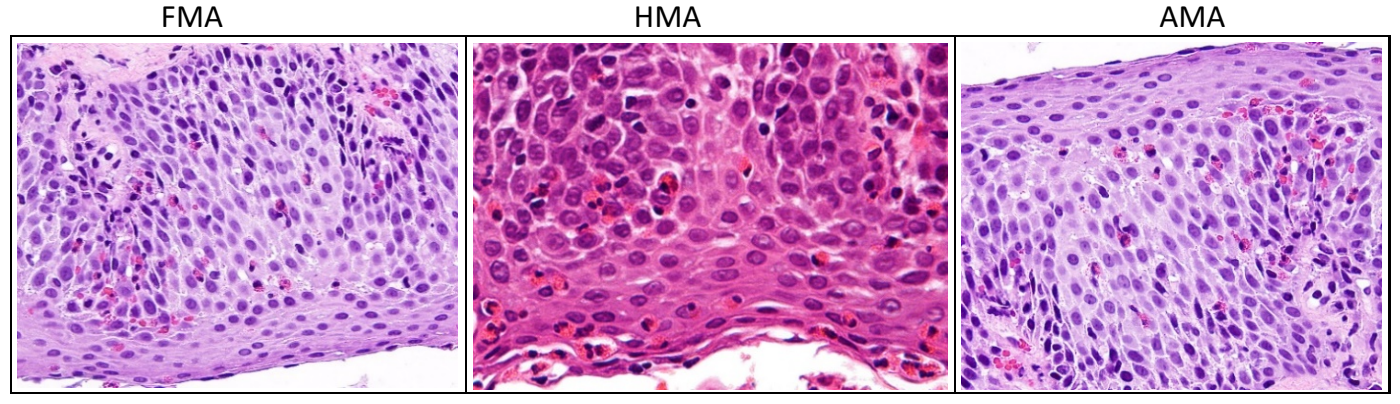

Figure 2. Histologic findings 
Table 1. Clinical features

\begin{tabular}{|c|c|c|c|}
\hline & FMA & HMA & AMA \\
\hline Childhood feature of allergy & Atopic dermatitis & Broncial asthma & $\begin{array}{l}\text { Urticaria, allergic rhinitis and difficulty } \\
\text { swallowing tablets }\end{array}$ \\
\hline CRP & 27 & 12 & 54 \\
\hline Peripheral Eosinophils & $11.5 \%$ & $8.7 \%$ & $9.1 \%$ \\
\hline Total IgE & 840 & 420 & 650 \\
\hline EGD & Fixed ring contractions with extensive exudates & Fixed ring contractions & Extensive exudates \\
\hline Esophageal biopsy & $>25$ eosinophils/hpf & 15-20 eosinophils/hpf & $>25$ eosinophils $/ \mathrm{hpf}$ \\
\hline Gastric biopsy & Eosinophils $<7 / \mathrm{hpf}$ & Eosinophils $<7 / \mathrm{hpf}$ & Eosinophils $<7 / \mathrm{hpf}$ \\
\hline Duodenal biopsy & Eosinophils $<7 / \mathrm{hpf}$ & Eosinophils $<7 / \mathrm{hpf}$ & Eosinophils $<7 /$ hpf \\
\hline
\end{tabular}

to the deeper layers [28] which maintains the allergic cascade. It was only after elimination of these proteins from their diet that they started to respond to topical steroids (Fluticasone 2 oral puffs three times daily) with continuation of the PPI at a high dose (Rabeprazole $20 \mathrm{mg}$ bd). Three months later as the first patient felt being normal and well he decided to re-use the same protein compounds to resume his body building program and this had led to a severe relapse of symptoms. Treatment was re-instated with fluticasone, Rabeprazole and the addition of Montelukast (a leukotriene analogue) $10 \mathrm{mg}$ once daily. This has provided a strong evidence that the protein compounds that he took were the initiators of this disease. The other two brothers were maintained on the topical steroid and rabeprazole for 8 weeks and medicine was withdrawn gradually thereafter. They are in a controlled state with no symptoms appearing since then.

\section{References}

1. Liacouras CA, Furuta GT, Hirano I, Atkins D, Attwood SE, et al. (2011) Eosinophilic Esophagitis: Updated consensus recommendations for children and adults. J Allergy Clin Immunol 128: 3-20. [Crossref]

2. Soon IS, Butzner JD, Kaplan GG, deBruyn JC (2013) Incidence and prevalence of eosinophilic esophagitis in children. J Pediatr Gastroenterol Nutr 57: 72-80. [Crossref]

3. Sealock RJ, Rendon G, El-Serag HB (2010) Systematic review: the epidemiology of eosinophilic oesophagitis in adults. Aliment Pharmacol Ther 32: 712-719. [Crossref]

4. Ronkainen J, Talley NJ, Aro P, Storskrubb T, Johansson SE, et al. (2007) Prevalence of oesophageal eosinophils and eosinophilic oesophagitis in adults: the population-based Kalixanda study. Gut 56: 615-620. [Crossref]

5. Straumann A, Simon HU (2005) Eosinophilic esophagitis: escalating epidemiology? $J$ Allergy Clin Immunol 115: 418-419. [Crossref]

6. Prasad GA, Alexander JA, Schleck CD, Zinsmeister AR, Smyrk TC, et al. (2009) Epidemiology of eosinophilic esophagitis over three decades in Olmsted County, Minnesota. Clin Gastroenterol Hepatol 7: 1055-1061. [Crossref]

7. Mackenzie SH, Go M, Chadwick B, Thomas K, Fang J, et al. (2008) Eosinophilic oesophagitis in patients presenting with dysphagia-a prospective analysis. Aliment Pharmacol Ther 28: 1140-1146. [Crossref]

8. Veerappan GR, Perry JL, Duncan TJ, Baker TP, Maydonovitch C, et al. (2009) Prevalence of eosinophilic esophagitis in an adult population undergoing upper endoscopy: a prospective study. Clin Gastroenterol Hepatol 7: 420-426. [Crossref]

9. Spergel JM, Brown-Whitehorn TF, Cianferoni A, Shuker M, Wang ML, et al. (2012) Identification of causative foods in children with eosinophilic esophagitis treated with an elimination diet. J Allergy Clin Immunol 130: 461-467. [Crossref]

10. Collins MH, Blanchard C, Abonia JP, Kirby C, Akers R, et al. (2008) Clinical, pathologic, and molecular characterization of familial eosinophilic esophagitis compared with sporadic cases. Clin Gastroenterol Hepatol 6: 621-629. [Crossref]

11. Blanchard C, Wang N, Rothenberg ME (2006) Eosinophilic esophagitis: pathogenesis, genetics, and therapy. J Allergy Clin Immunol 118: 1054-1059. [Crossref]
12. Ober C (2005) Perspectives on the past decade of asthma genetics. J Allergy Clin Immunol 116: 274-278. [Crossref]

13. Straumann A, Schoepfer AM (2012) Therapeutic concepts in adult and paediatric eosinophilic oesophagitis. Nat Rev Gastroenterol Hepatol 9: 697-704. [Crossref]

14. Spergel JM (2007) Eosinophilic esophagitis in adults and children: evidence for a food allergy component in many patients. Curr Opin Allergy Clin Immunol 7: 274-278. [Crossref]

15. Kelly K, Lazenby A, Rowe P, Yardley JH, Perman JA, et al. (1995) Eosinophilic esophagitis attributed to gastroesophageal reflux: improvement with an amino acid based formula. Gastroenterology 109: 1503-1512. [Crossref]

16. Henderson CJ, Abonia JP, King EC, Putnam PE, Collins MH, et al. (2012) Comparative dietary therapy effectiveness in remission of pediatric eosinophilic esophagitis. $J$ Allergy Clin Immunol 129: 1570-1578. [Crossref]

17. Markowitz JE, Spergel JM, Ruchelli E, Liacouras CA (2003) Elemental diet is an effective treatment for eosinophilic esophagitis in children and adolescents. $\mathrm{Am} \mathrm{J}$ Gastroenterol 98: 777-782. [Crossref]

18. Peterson KA, Byrne KR, Vinson LA, Ying J, Boynton KK, et al. (2013) Elemental diet induces histologic response in adult eosinophilic esophagitis. Am J Gastroenterol 108: 759-766. [Crossref]

19. Cheung KM, Oliver MR, Cameron DJS, Catto-Smith AG, Chow CW (2003) Esophageal eosinophilia in children with dysphagia. J Pediatr Gastroenterol Nutr 37: 498-503. [Crossref]

20. Liacouras CA, Spergel JM, Ruchelli E, Verma R, Mascarenhas M, et al. (2005) Eosinophilic esophagitis: a 10-year experience in 381 children. Clin Gastroenterol Hepatol 3: 1198-1206. [Crossref]

21. Noel RJ, Putnam PE, Rothenberg ME (2004) Eosinophilic esophagitis. N Engl J Med 351: 940-941. [Crossref]

22. Sant'Anna AM, Rolland S, Fournet JC, Yazbeck S, Drouin E (2004) Eosinophilic esophagitis in children: symptoms, histology and $\mathrm{pH}$ probe results. $J$ Pediatr Gastroenterol Nutr 39: 373-377. [Crossref]

23. Straumann A, Spichtin HP, Grize L, Bucher KA, Beglinger C, et al. (2003) Natural history of primary eosinophilic esophagitis. Gastroenterology 125: 1660-1669.

24. Dellon ES (2012) Diagnosis and management of eosinophilic esophagitis. Clin Gastroenterol Hepatol 10: 1066-1078. [Crossref]

25. Dellon ES (2013) Eosinophilic esophagitis. Gastroenterol Clin North Am 42: 133-153. [Crossref]

26. Papadopoulou A, Dias JA (2014) Eosinophilic esophagitis: an emerging disease in childhood-review of diagnostic and management strategies. Front Pediatr 2: 129. [Crossref]

27. Lamousé-Smith ES, Furuta GT (2006) Eosinophils in the gastrointestinal tract. Curr Gastroenterol Rep 8: 390-395. [Crossref]

28. Barlow WJ, Orlando RC (2005) The pathogenesis of heartburn in nonerosive reflux disease: a unifying hypothesis. Gastroenterology 128: 771-778. [Crossref]

Copyright: (C2018 Dajani A. This is an open-access article distributed under the terms of the Creative Commons Attribution License, which permits unrestricted use, distribution, and reproduction in any medium, provided the original author and source are credited. 